\title{
Assessment of safety and tolerability of remogliflozin etabonate (GSK189075) when administered with total daily dose of 2000 mg of metformin
}

Robert Dobbins ${ }^{1}$, Elizabeth K. Hussey ${ }^{2}$, Robin O'Connor-Semmes ${ }^{3}$, Susan Andrews ${ }^{4}$, Wenli Tao ${ }^{5}$, William O. Wilkison ${ }^{6}$, Bentley Cheatham ${ }^{6 *}$, Katare Sagar ${ }^{7}$ and Barkate Hanmant ${ }^{7}$

\begin{abstract}
Background: Patients with type 2 diabetes mellitus (T2DM) are characterized by an elevated glycemic index and are at a higher risk for complications such as cardiovascular disease, nephropathy, retinopathy and peripheral neuropathy. Normalization of glycemic index can be achieved by dosing combinations of metformin with other anti-diabetic drugs. The present study (Clintrials number NCT00519480) was conducted to evaluate the safety, tolerability, pharmacokinetics and pharmacodynamics of remogliflozinetabonate, an SGLT2 inhibitor, withdoses (500 mg and $750 \mathrm{mg} \mathrm{BID)} \mathrm{greater} \mathrm{than} \mathrm{the} \mathrm{commercial} \mathrm{dose} \mathrm{(100} \mathrm{mg} \mathrm{BID)in} \mathrm{combination} \mathrm{with} \mathrm{metformin} \mathrm{with}$ minimum daily dose of $2000 \mathrm{mg}$ given in two divided doses.

Methods: This was a randomized, double-blinded, repeat dose study in 50 subjects with T2DM. The study was conducted in three phases; run-in, randomization, and treatment. All subjects were on a stable metformin dosing regimen. Cohort 1 subjects were randomly allocated to receive either remogliflozin etabonate $500 \mathrm{mg}$ BID or placebo BID (2:1) in addition to metformin. Cohort 2 subjects were administered with either remogliflozin etabonate $750 \mathrm{mg} \mathrm{BID}$ or placebo BID (2:1) in addition to metformin for 13 days. All the subjects were assessed for safety (adverse events, lactic acid levels, vital signs, electrocardiogram [ECG]), pharmacokinetic evaluation, and pharmacodynamics (Oral Glucose Tolerance Testing) parameters.

Results: Co-administration of remogliflozin etabonate and metformin was well tolerated in all subjects during the observation period. There were no severe or serious adverse events (SAEs) and no increase in lactic acid concentration was reported during the study. The statistical results showed that concomitant administration of remogliflozin etabonate, either $500 \mathrm{mg}$ or $750 \mathrm{mg}$ BID, with metformin had no effect on the pharmacokinetics of metformin. The accumulation ratios, Day 13 vs. Day 1, for AUC values of remogliflozin etabonate and its metabolites were all very close to 1 , indicating no accumulation in plasma concentrations of remogliflozin etabonate and its metabolites. Mean glucose values from baseline and glucose and insulin values following oral glucose tolerance test (OGTT) were decreased in all treatment groups.
\end{abstract}

\footnotetext{
* Correspondence: Bentley@avolynt.com

${ }^{6}$ Avolynt, Inc., RTP, 3920 South Alston Avenue, Durham, NC 27713, USA

Full list of author information is available at the end of the article
} 
Conclusion: Co-administration of doses of remogliflozin etabonate (500 mg BID or $750 \mathrm{mg}$ BID) greater than the commercial dose (100 mg BID) with metformin (2000 mg BID) was shown to be safe and effective during the observation period.

Trial registration: ClinicalTrials.gov, NCT00519480. Registered:22 August 2007.

Keywords: Lactic acidosis, Metformin, Pharmacokinetics, Pharmacodynamics, Remogliflozin etabonate, Remogliflozin, Safety, SGLT2 inhibitor, Sodium-glucose transporters (SGLTs), Type 2 diabetes mellitus

\section{Research in context}

- What is already known about this subject? $>$ Patients with type 2 diabetes mellitus (T2DM) show an elevated glycemic index and are at a higher risk for serious complications, Metformin is a well known antidiabetic drug, Lower dose of Remogliflozin Etabonate in combination with metformin is safe and effective

- What is the key question?

$>$ To evaluate whether higher doses Remogliflozin Etabonate in combination with metformin is safe and effective.

- What are the new findings?

$>$ The co-administration of Remogliflozin Etabonate (500 or $750 \mathrm{mg}$ BID) and Metformin (> $2000 \mathrm{mg} /$ day) was found to be safe and tolerable in T2DM patients, with no metabolic disturbances observed. $>$ Body weight was reduced in all treatment groups; however, $1 \mathrm{~kg}$ more was lost in the RE groups compared to metformin alone.

$>$ Observed reduction in fasting glucose and OGTT levels suggest potential improvement in glycemia with RE in patients already on high-dose of metformin

- How might this impact on clinical practice in the foreseeable future?

$\triangle$ As metformin is widely used antidiabetic agent, $\mathrm{RE}$ will be used in combination with metformin in treating subjects with T2DM. This study demonstrates safety and tolerability, and to some extent efficacy, in T2DM when RE and metformin is used for T2DM in clinical practice.

\section{Background}

Type 2 diabetes mellitus (T2DM) is a chronic, metabolic disease with symptomatic hyperglycemia and is associated with a higher risk for complications such as cardiovascular disease, nephropathy, retinopathy and peripheral neuropathy [1]. As per the International Diabetes Federation, 425 million people have diabetes and this number is expected to rise to 629 million by 2045 [2]. Diabetic complications can be managed by keeping blood glucose levels within normal ranges. Treatment guidelines from the
American Diabetes Association and European Association for the Study of Diabetes recommend metformin, along with diet and exercise, as a first line therapy followed by adding second-line agents to these patients with insufficient control of hyperglycemia [3]. However, despite the use of multiple medications to control patients' blood glucose levels, two thirds of patients with T2DM remain unable to reach their HbA1c targets [4]. Therefore, development of new anti-diabetic drugs is needed but the combination or compatibility of metformin with other drugs becomes a serious challenge in developing new anti-diabetic therapies.

Metformin is an oral anti-hyperglycemic drug which decreases blood glucose levels by decreasing hepatic glucose production (gluconeogenesis), decreasing the intestinal absorption of glucose, and increasing insulin sensitivity by increasing peripheral glucose uptake and utilization [5]. Lactic acidosis is a serious adverse event (AE) associated with metformin administration and has been labeled as such as a warning by the FDA [6, 7]. Hyperglycemia can also be controlled by increasing renal glucose excretion via inhibition of sodium-glucose transporters (SGLTs) [8]. SGLT1 and SGLT2 are found in the kidney and are responsible for the majority of glucose reabsorption (10 and 90\%, respectively). Vallon et al. reported that fractional renal reabsorption of glucose is reduced in mice lacking the SGLT2 gene as compared to wild-type mice [9]. Previously published studies with diabetic patients revealed SGLT2 inhibition lowers plasma glucose levels via urinary glucose excretion [10].

Remogliflozin Etabonate (RE) is a novel and potent inhibitor of SGLT2, and studies have reported a safe and effective response of RE in lowering the plasma glucose concentration in patients suffering with T2DM $[11,12]$. In vitro analyses have also reported a low clinical drug interaction risk for remogliflozin etabonate because of availability of multiple biotransformation pathways [13].

In a previously published study, concomitant administration of RE (500 mg BID) and metformin (500 mg BID) for 3 days was well tolerated. Remogliflozin etabonate had no effect on the steady-state plasma profiles of metformin, and metformin had no effect on the pharmacokinetics of RE or its metabolites [14]. The present study was conducted to evaluate the safety, pharmacokinetics and pharmacodynamic analysis of concomitant administration of 
metformin ( $\geq 2000 \mathrm{mg} /$ day) and RE (500 mg BID, $750 \mathrm{mg}$ BID) over a longer duration (13 days) and in a larger number of (50) subjects with T2DM.

\section{Methods}

\section{Study design}

This was a randomized, double-blinded, repeat dose parallel group study. Subjects currently taking metformin for the treatment of T2DM and fulfilling the inclusion criteria were recruited. The study protocol was approved by the institutional review board (IRB) and the study was conducted in accordance with the major ethical principles specified in the Declaration of Helsinki and good clinical practice (GCP) guidelines. Written informed consent was obtained from each subject before any study related procedure was performed. This was a multicenter study conducted at a total of four centers: two centers in the USA, one center in Germany, and one center in Argentina. The study protocol, any amendments, the informed consent, and other information were reviewed and approved by relevant ethics committee or review board at each study center.

The study was comprised of three phases; run-in, randomization, and treatment. In the run-in phase, subjects who were taking $<2000 \mathrm{mg}$ of metformin were titrated up over a 14-day period to a minimum daily dose of $2000 \mathrm{mg}$ immediate release metformin. If subjects were taking metformin once daily (QD) or three times daily (TID), then they were titrated to BID for the duration of the study. Following the run-in phase, treatment phase of 13 days included in-house assessment in clinical research unit from day -2 to day 4 and day 12 to day 14 and outpatient basis assessment from Day 5 to Day 11 with follow-up visit from Day 21-24. In treatment phase the patients were considered in two cohorts. Cohort 1 subject were randomly allocated to receive either RE $500 \mathrm{mg}$ BID or placebo BID (2:1) in addition to metformin. Cohort 2 subjects received either RE $750 \mathrm{mg}$
BID or placebo BID (2:1) in addition to metformin. Cohort 2 dosing commenced after at least 18 subjects in Cohort 1 had completed dosing and preliminary safety information had been reviewed (Fig. 1). The decision to begin Cohort 2 was based upon blinded review of AE reports, vital signs, ECG findings and clinical laboratory results by the site physicians and medical monitor.

\section{Treatment assignment}

Treatment assignments were in accordance with the randomization schedule stratified by cohort with fixed block size. Upon successful completion of the metformin titration period, each subject is randomly assigned to one of the two cohorts with either one of the two RE dose regimens or placebo in a ratio of 2:1. A central randomization was applicable for all sites, and performed using a GSK proprietary IWRS randomization system.

\section{Sample size}

The sample size planned for this study arose primarily from practical feasibility. There was no formal calculation of power or sample size. However, considering mean difference of plasma lactate level between treatment and placebo as one of evaluable end-points, a sample size estimation using the plasma lactate levels had been determined. A sample size of 12 subjects or 16 subjects with evaluable data completed for each active arm and placebo arm was estimated. This was based on larger inter-subject standard deviation of lactate level of $0.45 \mathrm{mmol} / \mathrm{L}$ in metformin alone group observed in previous report of 3-day metformin-RE drug-drug interaction study [15].

\section{Inclusion and exclusion criteria}

Men and women (with adequate birth control, if of childbearing potential) aged 30-64 years (both inclusive) having a body mass index (BMI) of $22-40 \mathrm{~kg} / \mathrm{m}^{2}$ with a

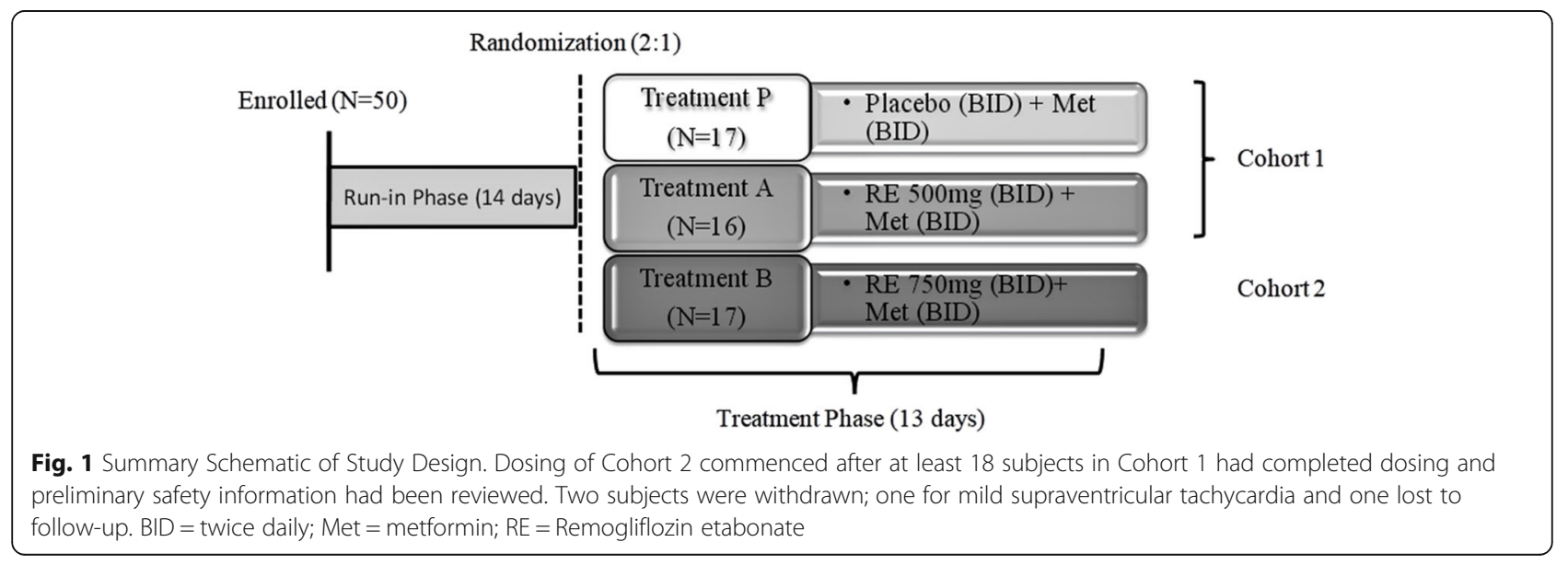


documented T2DM diagnosis (diagnosed not less than 3 months; HbAlc range from 7 to $<10 \%$ and fasting plasma glucose $(\mathrm{FPG})<280 \mathrm{mg} / \mathrm{dL}$ at screening, fasting $\mathrm{C}$-peptide lower limit of the reference range for an approved local laboratory assay) who were not adequately controlled by monotherapy with metformin were included in the study. Only those subjects were included who were willing and medically able to titrate their metformin dose to at least $2000 \mathrm{mg} /$ day for 2 weeks, if on a lesser dose and have FPG $>126 \mathrm{mg} / \mathrm{dL}$ near the end of the run-in period.

Subjects with a prior history of autoimmune type 1 diabetes mellitus, diabetic ketoacidosis or lactic acidosis, gastrointestinal, hepatic or renal diseases were excluded from the study. Subjects requiring insulin therapy and any other anti-diabetic drug were also excluded from the study.

\section{Study objectives}

The primary objective of the study was to access the safety and tolerability of RE (500 mg and $750 \mathrm{mg}$ twice daily) along with metformin at doses $2000 \mathrm{mg}$ daily in subjects with T2DM in terms of incident adverse events including hypoglycemia, plasma lactic acid levels and lactate levels and clinically relevant changes in vital signs and laboratory assessments.

The secondary objectives included the assessment of the effect of RE on steady state plasma concentrations of metformin, pharmacokinetics of RE and key metabolites while on metformin treatment and the response to an oral glucose tolerance test (OGTT) when RE was added to metformin versus metformin alone. The study assessment therefore included safety assessments (adverse events, hypoglycemia, plasma lactic acid level and lactic acidosis events, vital signs, ambulatory blood pressure monitoring, ECG, clinical laboratory values, fluid balance and body weight) as well as pharmacokinetic sampling, and plasma glucose, plasma insulin levels after OGTT.

\section{Adverse event monitoring}

The adverse events monitoring included recording of any adverse event (AE) and serious adverse event (SAE) reported or observed during the entire study and followup period. All the subjects were counseled to inform study staff of any AEs that occurred during the study. Any abnormal laboratory findings (e.g., clinical chemistry, hematology, and urinalysis) or other abnormal assessments (e.g., ECGs, vital signs, physical examination) that were judged by the investigator as clinically significant were recorded as AEs or SAE.

\section{Clinical laboratory evaluations}

For all measures, blood sample was obtained prior to having breakfast and were collected on baseline (Day-1), mornings (prior to first dose and breakfast) of Day 1, 2, 3, and 4 (inpatient) and Days 6, 8, and 10 (outpatient) and Days 13 and 14 (inpatient). Free fatty acids (FFAs) were also measured on Day-1 and 13. Samples were kept at $4{ }^{\circ} \mathrm{C}$ and were analyzed immediately.

\section{Surveillance for lactic acidosis}

The samples for acidosis analysis were collected at screening (following an overnight fast and prior to morning dose), once during the run-in phase, at baseline (Day-1), mornings (prior to first dose and breakfast) of Days 1, 2, 3, and 4 (inpatient) and Days 6, 8, and 10 (outpatient) and Days 13 and 14 (inpatient). Subjects were not allowed to do rigorous exercise or physical labor during the treatment phase of the study and instructed to limit exercise $12 \mathrm{~h}$ before sampling.

\section{Electrocardiogram}

A 12-lead ECG was performed at the Screening Visit, Day- 1, pre-dose Days 4, 6, 8, 10, and 13; and at the follow-up Visit.

\section{Fluid balance assessments}

The amount of all liquids consumed and urine volume were collected beginning the morning of Day 1 (prior to metformin dose) and the morning of Day 13 (prior to metformin and RE dosing), and continued until the subject was discharged from the clinical research facility after completing the inpatient portions of the study.

\section{Body weight}

Body weight measurement was performed at screening and during inpatient Days- 1, 2, 4, 8, 13, and 14.

\section{Ambulatory blood pressure monitoring}

The ambulatory blood pressure was monitored for 24 during inpatient days (beginning Day 1 at 08.00, Day 2 at 08.00 and Day 13 at 08.00 ). The unit was programmed to take blood pressure readings every $10 \mathrm{~min}$ from 08.00 to 10.00 , every $20 \mathrm{~min}$ from 10.00 to 22.00 , and every 30 min from 22.00 to 08.00 the following morning.

\section{Pharmacokinetic analysis}

Serial blood samples $(2 \mathrm{ml})$ were collected on Day 1 and Day 13 at different time-points for the determination of remogliflozin etabonate, remogliflozin (GSK189074), GSK279782 and metformin concentrations in plasma; pre-dose (within $10 \mathrm{~min}$ prior to next dose), 15, 30, 45 min and 1, 1.5, 2, 2.5, 3, 4, 6, 8, 10 and $12 \mathrm{~h}$ (before second dose of the day). PK analysis was conducted by INDAPharma, LLC (Chapel Hill, NC, USA), under the direction of Clinical Pharmacokinetics/Modelling and Simulation, GSK using the non-compartmental analysis Model 200 (for extra vascular administration) of 
WinNonlin Professional Edition version 4.1 (Pharsight Corporation, Mountain View, CA). The drug assay techniques utilized for each of the drug and metabolites has been reported prior [14].

\section{Pharmacodynamic analysis}

Oral glucose tolerance testing was performed on Day 1 and Day 13 using a $75 \mathrm{~g}$ oral glucose solution. Blood samples for the measurement of insulin and glucose were taken immediately before drug dosing (within 5 min of drug dosing), and at $30 \mathrm{~min}, 1,1.5,2,3,4$, and 6 $\mathrm{h}$ following drug dosing.

\section{Statistical analysis}

Descriptive statistics were used to summarize baseline demographics, safety data, and pharmacokinetic parameters. Geometric mean and $\% \mathrm{CV}_{\mathrm{b}}$ (between-subject coefficient of variation) were calculated for all pharmacokinetic parameters except $t_{\max }$. Comparisons of placebo with each active dose of RE were assessed in terms of change from baseline in fasting plasma lactate acid using repeated measures analysis of covariance model. The model included terms for baseline measurement, visit, treatment and visitby-treatment interaction. The same model was applied to change from baseline in weighted means of day-time, night-time and $0-24 \mathrm{~h}$ of blood pressures. Within group treatment comparison was performed using mixed model on log transformed $\mathrm{C}_{\max }$ and $\mathrm{AUC}(0$-last).

\section{Results}

A total of 50 subjects were enrolled in the study. Two subjects were withdrawn from the study; one due to an $\mathrm{AE}$ (supraventricular tachycardia) and one was lost to follow-up. Thus, 48 subjects (men [44\%], women [56\%]) completed the study as planned and were included in the analyses. The mean age of the included patients was 54 years (range 40 to 60 years) and the mean BMI was
$30 \mathrm{~kg} / \mathrm{m}^{2}$ (range $23-40 \mathrm{~kg} / \mathrm{m}^{2}$ ). The mean duration of exposure to remogliflozin etabonate was 12.4 days during RE $500 \mathrm{mg}+$ metformin, 12.7 days during RE $750 \mathrm{mg}+$ metformin, and 13 days during placebo treatment.

\section{Safety and tolerability}

The occurrence of adverse events by the treatment groups have been enlisted in Table 1. All AEs reported during the study were mild in intensity and resolved spontaneously. One subject was withdrawn from the study on Day 3, due to an AE of supraventricular tachycardia, which was not an SAE. The most commonly reported AEs were diarrhea $(10 \% ; N=5 / 50)$, nausea $(6 \%$; $N=3 / 50)$ thirst, vomiting and dizziness $(4 \% ; N=2 / 50)$. After treatment, urinary tract infection and dyslipidemia were reported in only 1 subject from each placebo and RE 500mg + metformin groups, respectively. The group administered with RE $750 \mathrm{mg}$ + metformin reported no post-therapy AEs. Two subjects had hypoglycemic laboratory events during the study, one each in placebo + metformin group (mild, resolved without intervention) and RE $750 \mathrm{mg}+$ metformin group (moderate, resolved with sweets). No other clinical laboratory values were reported as AEs in the run-in phase, or during the treatment Phase. No significant changes or trends in vital signs or ECGs were observed during the treatment period.

Mean plasma fasting lactic acid decreased over time during dosing from Day 2 to Day 13 for subjects in Cohort 1 and 2 and appeared to increase slightly from Day 2 to Day 13 in the placebo group (Fig. 2). The mean maximum on-therapy fasting lactic acid values were not increased in the RE-containing treatments compared to placebo treatment (Table 2).

Statistically significant differences (decreases) in change from baseline fasting plasma lactic acid were observed between the two treatment groups versus placebo

Table 1 Analysis of All Drug-Related and Post-Therapy Adverse Events

\begin{tabular}{|c|c|c|c|}
\hline Adverse Event & $\begin{array}{l}\text { Placebo + Metformin } \\
(N=17)\end{array}$ & $\begin{array}{l}\text { RE } 500 \mathrm{mg}+\text { Metformin } \\
(N=16)\end{array}$ & $\begin{array}{l}\text { RE } 750 \mathrm{mg}+\text { Metformin } \\
(N=17)\end{array}$ \\
\hline \multicolumn{4}{|l|}{ All Adverse Event (AE) N(\%) } \\
\hline Any AE & $3(18 \%)$ & $6(38 \%)$ & $4(24 \%)$ \\
\hline Diarrhoea & $1(6 \%)$ & $3^{\mathrm{a}}(19 \%)$ & $1(6 \%)$ \\
\hline Nausea & $1^{\mathrm{a}}(6 \%)$ & $1(6 \%)$ & $1(6 \%)$ \\
\hline Thirst & $1(6 \%)$ & 0 & $1^{\mathrm{a}}(6 \%)$ \\
\hline Vomiting & 0 & $1^{\mathrm{a}}(6 \%)$ & $1(6 \%)$ \\
\hline Dizziness & 0 & $1(6 \%)$ & $1(6 \%)$ \\
\hline Supraventricular tachycardia & 0 & $1^{\mathrm{a}}(6 \%)$ & 0 \\
\hline Urinary tract infection & $1^{\mathrm{b}}(6 \%)$ & & 0 \\
\hline Dyslipidemia & 0 & $1^{\mathrm{b}}(6 \%)$ & 0 \\
\hline
\end{tabular}

AE Adverse event, RE Remogliflozinetabonate ${ }^{\text {a }}$ determined to be drug related adverse event, one of 3 events of diarrhoea with RE 500 mg + Met determined to be drug related, ${ }^{\mathrm{b}}$ post therapy adverse events occurred after last dose 


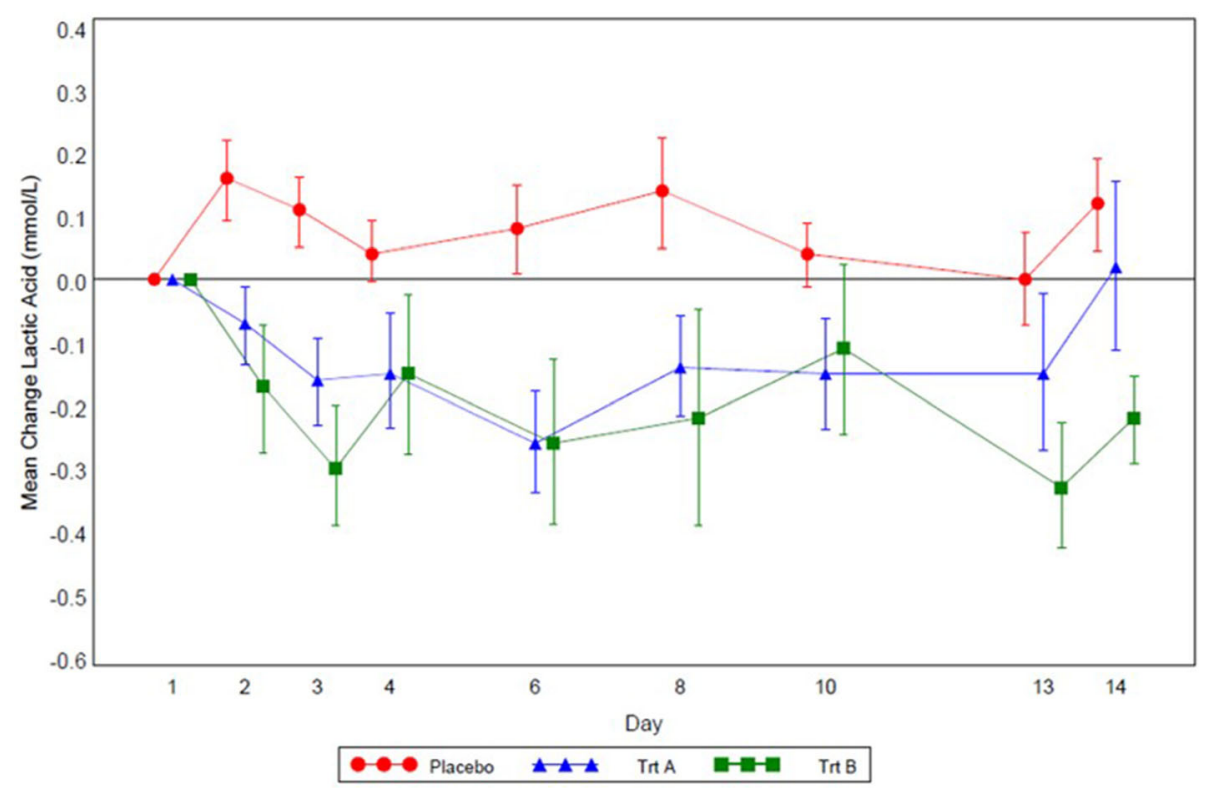

Fig. 2 Plot of Mean ( \pm standard error) Change from Baseline in Fasting Plasma Lactic Acid Concentration (mmol/L). Trt A, Remogliflozin Etabonate 500 mg + metformin; Trt B, Remogliflozin Etabonate 750 mg + metformin

on most Study Days. In terms of events, five subjects had a lactic acid greater than the upper limits of normal (ULN) at anytime during the study; in four subjects the elevations occurred while receiving metformin alone and in one subject receiving RE. None of the elevations were sustained and all were minimally above the ULN. No subject was withdrawn for increased lactic acid or any other metabolic abnormality.

Ambulatory blood pressure monitoring measured decreases from baseline in systolic and diastolic readings at nighttime (midnight to $6 \mathrm{am}$ ) on Day 13 were significantly different for both RE regimens compared to placebo (metformin alone). The systolic blood pressure decreased significantly by $8.4 \mathrm{mmHg}$ for the RE $500 \mathrm{mg}$ and $7.1 \mathrm{mmHg}$ for the RE $750 \mathrm{mg}$ in Night time. Likewise, diastolic blood pressure decreased significantly by $6.5 \mathrm{mmHg}$ for the RE $500 \mathrm{mg}$ and $4.8 \mathrm{mmHg}$ for the RE $750 \mathrm{mg}$ in night time. However, reductions observed over the daytime ( $10 \mathrm{am}$ to $8 \mathrm{pm})$ and the entire $24-\mathrm{h}$ periods were not statistically significant (Table 3 ).

\section{Pharmacokinetics}

The metformin mean AUC (0-tau) $[13,895$ vs 14,693 (hr.ng/mL)] and $C_{\max }[2162$ vs $2166(\mathrm{ng} / \mathrm{mL})]$ values were comparable between Day-1 (metformin alone) and Day 13 (RE $500 \mathrm{mg}+$ metformin group); mean AUC (0-tau) ratio $(90 \% \mathrm{CI})$ was $1.03(0.97,1.09)$ (Table 4$)$. Median $t_{\max }$ values were also equivalent [3.0 vs $2.5 \mathrm{~h}$ ]. The metformin mean AUC (0-tau) [11,319 vs 11,392 (hr.ng/ $\mathrm{mL})]$ and $\mathrm{C}_{\max }[1758$ vs $1695(\mathrm{ng} / \mathrm{mL})]$ values were comparable between Day-1 (metformin alone) and Day 13
(RE $750 \mathrm{mg}+$ metformin group). The mean AUC (0-tau) ratio $(90 \% \mathrm{CI})$ was $1.03(0.97,1.09)$ and $1.01(0.88,1.16)$ for the RE $500 \mathrm{mg}+$ metformin and RE $750 \mathrm{mg}$ + metformin groups, respectively (Table 5 ).

In the RE $500 \mathrm{mg}$ group, remogliflozin, the active form of the prodrug, was formed with peak concentrations ranging from 0.5 to about $6.0 \mathrm{~h}$. The mean AUC (0-tau) [4894 vs 4928 (hr.ng/mL)] and $C_{\max }$ [1999 vs 1494 (ng/ $\mathrm{mL})$ ] values were comparable between Day 1 and Day 13 (Table 6). The mean $\mathrm{AUC}_{(0 \text {-tau) }}$ accumulation ratio (90\% CI) was $1.00(0.91,1.10)$ for $\mathrm{RE} 500 \mathrm{mg}+$ metformin (Table 7).

In the RE $750 \mathrm{mg}$ group, the remogliflozin mean AUC $_{(0-\text { tau })}[8515$ vs $6996(\mathrm{hr} . n \mathrm{~g} / \mathrm{mL})]$ and $\mathrm{C}_{\max }[4008$ vs $2508(\mathrm{ng} / \mathrm{mL})]$ values were modestly different between Day 1 and Day 13 (Table 6). The mean $\mathrm{AUC}_{(0-\text { tau }}$ accumulation ratio $(90 \% \mathrm{CI})$ was $0.82(0.755,0.899)$ (Table 7$)$.

\section{Pharmacodynamics}

The mean plasma glucose values for RE $500 \mathrm{mg}+$ metformin and RE $750 \mathrm{mg}$ + metformin were decreased from 13 to $9 \mathrm{mmol} / \mathrm{L}$ and 11 to $8 \mathrm{mmol} / \mathrm{L}$ within 13 days, respectively. Similarly, the mean insulin values were also decreased in all the three treatment groups (Table 8).

Body weight decreased in all treatment groups including placebo; however, subjects who received RE lost $1 \mathrm{~kg}$ more weight, $(-2.03 \mathrm{~kg}$ for RE $500 \mathrm{mg}+$ metformin and $-1.84 \mathrm{~kg}$ for RE $750 \mathrm{mg}+$ metformin) by Day 14 than those who received placebo $(-1.02 \mathrm{~kg}$ for placebo + metformin) (Table 8). 
Table 2 Summary of Fasting Plasma Lactic Acid Concentration

\begin{tabular}{|c|c|c|c|}
\hline Lactic acid (mmol/L) & $\begin{array}{l}\text { Placebo + Metformin } \\
(N=17)\end{array}$ & $\begin{array}{l}\text { RE } 500 \mathrm{mg}+\text { Metformin } \\
(N=16)^{\mathrm{a}}\end{array}$ & $\begin{array}{l}\text { RE } 750 \mathrm{mg} \text { + Metformin } \\
(N=17)^{\mathrm{b}}\end{array}$ \\
\hline \multicolumn{4}{|c|}{ A. Summary of Maximum On-Therapy Absolute concentrations and Changefrom Baseline; Mean (SD) } \\
\hline Absolute Values & $1.554(0.5094)$ & $1.220(0.2684)$ & $1.508(0.4389)$ \\
\hline Change From Baseline & $0.460(0.2289)$ & $0.234(0.3717)$ & $0.249(0.5934)$ \\
\hline \multicolumn{4}{|c|}{ B. Summary of Repeated measures analysis ofcovariance of change from baseline (vs. placebo) on selected days } \\
\hline \multicolumn{4}{|l|}{ Study Day 2} \\
\hline Mean (SD) & $0.16(0.266)$ & $-0.07(0.248)$ & $-0.17(0.419)$ \\
\hline Difference $(95 \% \mathrm{Cl})$ & & $-0.284(-0.485,-0.083)$ & $-0.246(-0.445,-0.047)$ \\
\hline$p$-value & & 0.0066 & 0.0164 \\
\hline \multicolumn{4}{|l|}{ Study Day 6} \\
\hline Mean (SD) & $0.08(0.288)$ & $-0.26(0.310)$ & $-0.26(0.538)$ \\
\hline Difference $(95 \%$ Cl) & & $-0.380(-0.603,-0.157)$ & $-0.254(-0.472,-0.036)$ \\
\hline$p$-value & & 0.0013 & 0.0232 \\
\hline \multicolumn{4}{|l|}{ Study Day 13} \\
\hline Mean (SD) & $0.00(0.304)$ & $-0.15(0.485)$ & $-0.33(0.398)$ \\
\hline Difference $(95 \% \mathrm{Cl})$ & & $-0.191(-0.414,0.031)$ & $-0.255(-0.475,-0.034)$ \\
\hline$p$-value & & 0.0905 & 0.0244 \\
\hline
\end{tabular}

Cl Confidence interval, RE Remogliflozin Etabonate, SD Standard deviation; ${ }^{a}: n=15$ for Day $6 \& 13 ;^{b}: n=16$ for Day 13

The treatment vs placebo difference is based on ANCOVA: Change $=$ Baseline + Treatment + Visit + Treatment-by-Visit

Total fluid intake, total urine volume, and fluid balance (intake - urine output) were also recorded during the study and these values were highly variable in all treatment groups.

\section{Discussion}

For patients with T2DM, metformin-based combination therapy is recommended when monotherapy is not enough to achieve targeted glycemic control [3]. Multiple doses and combinations of anti-hyperglycemic agents with negligible drug-drug interactions are preferred. This study was conducted to access the potential for metabolic disturbances that can lead to severe AEs in combination therapy $[16,17]$. In a previous study, the safety and effectiveness of a combination of RE $(500 \mathrm{mg}$ BID) with metformin (500 mg BID) in13 subjects with
T2DM for a duration 3 days was reported with no safety signals [14]. The aim of the current study was to evaluate the safety, pharmacokinetics and pharmacodynamics of concomitant administration of higher doses of metformin ( $\geq 2000 \mathrm{mg}$ total daily dose) with RE $500 \mathrm{mg}$ BID and $750 \mathrm{mg}$ BID over a longer duration (13 days) and in a larger number of (50) patients with T2DM.The current analysis too did not observe any safety signals on adverse events, hypoglycemia or laboratory or ECG assessments on concomitant administration of high dose ranges of $\mathrm{RE}$ and metformin $\geq 2000 \mathrm{mg}$ daily.

One potentially life-threatening side effect of metformin is lactic acidosis, as metformin in therapy increases the fasting plasma lactate in patients with T2DM [14, 18]. The previously published study reported a decrease in plasma lactic acid concentration, during co-

Table 3 Summary of AmbulatoryBlood pressure monitoring

\begin{tabular}{llll}
\hline Time & $\begin{array}{l}\text { Reading (Adjusted Mean Change } \\
\text { from Baseline inmmHg; } \boldsymbol{p} \text {-value) }\end{array}$ & RE $\mathbf{5 0 0} \mathbf{~ m g}+$ Metformin(N=14) & RE 750 $\mathbf{~ m ~ + ~ M e t f o r m i n ( ~}(\mathbf{N}=\mathbf{1 4})$ \\
\hline $24 \mathrm{~h}$ & Systolic & $-2.8 ; p=0.303$ & $-4.0 ; p=0.131$ \\
& Diastolic & $-2.0 ; p=0.256$ & $-3.3 ; p=0.062$ \\
Daytime & Systolic & $-3.4 ; p=0.291$ & $-2.4 ; p=0.441$ \\
& Diastolic & $-1.8 ; p=0.461$ & $-1.3 ; p=0.586$ \\
Nighttime & Systolic & $-8.4 ; p=0.020$ & $-7.1 ; p=0.047$ \\
& Diastolic & $-6.5 ; p=0.006$ & $-4.8 ; p=0.043$ \\
\hline
\end{tabular}

$B P$ Blood pressure, RE Remogliflozin Etabonate

The changes were ANCOVA adjusted mean change from baseline to Day 13 vs. Placebo 
Table 4 Summary of Pharmacokinetic Parameters of Metformin

\begin{tabular}{|c|c|c|c|c|c|c|}
\hline \multirow[t]{2}{*}{ Treatment } & \multicolumn{3}{|c|}{ Day- 1 Metformin alone } & \multicolumn{3}{|c|}{ Day 13 Metformin + RE } \\
\hline & $\begin{array}{l}\text { AUC } \\
\text { (0-tau) } \\
\text { (hr.ng/mL) }\end{array}$ & $\begin{array}{l}C_{\max } \\
(\mathrm{ng} / \mathrm{mL})\end{array}$ & $\begin{array}{l}t_{\max } \\
(\mathrm{hr})\end{array}$ & $\begin{array}{l}\text { AUC } \\
\text { (0-tau) } \\
\text { (hr.ng/mL) }\end{array}$ & $\begin{array}{l}C_{\max } \\
(\mathrm{ng} / \mathrm{mL})\end{array}$ & $\begin{array}{l}t_{\max } \\
(\mathrm{hr})\end{array}$ \\
\hline Metformin + & 12,305 & 1967 & 2.0 & 13,955 & 2041 & 2.5 \\
\hline Placebo & $(20)$ & (22) & $(0.5-4.0)$ & (24) & (24) & $(0.75-8.0)$ \\
\hline Metformin + & 13,895 & 2162 & 3.0 & 14,693 & 2166 & 2.5 \\
\hline RE $500 \mathrm{mg}$ & $(24)$ & (24) & $(0.5-4.0)$ & (25) & (28) & $(0.75-4.0)$ \\
\hline Metformin + & 11,319 & 1758 & 2.5 & 11,392 & 1695 & 2.0 \\
\hline RE $750 \mathrm{mg}+$ & (33) & (26) & $(0.5-4.0)$ & (37) & (34) & $(0.5-4.1)$ \\
\hline
\end{tabular}

RE Remogliflozin Etabonate

Values are geometric mean $(\% \mathrm{CVb})$ for each parameter, except for $t_{\max }$ which are median (range)

administration of RE with metformin, and no symptoms of lactic acidosis were observed [14]. In the current analysis, a decrease in fasting plasma lactic acid concentrations with the addition of RE to subjects stably dosed with metformin was observed. No subjects were withdrawn from this study for an elevated lactic acid or metabolic abnormality.

The inhibition of SGLT2 in the kidney with resulting increases in glycosuria a relatively new therapeutic modality for the treatment of subjects with T2DM. Remogliflozin etabonate is an orally available, novel, potent inhibitor of SGLT2, and has been shown in numerous clinical trials to be a safe and efficacious monotherapy for the treatment of T2DM [12, 19-21].

O'Connor-Semmes et al. have demonstrated the repeat dosing PK of RE showed only $10 \%$ increase in AUC and $t_{1 / 2}$, indicating no accumulation of RE in plasma concentrations [20]. Similarly, Mikhail et al. opined that RE and its metabolites (remogliflozin and GSK279782) not only lowers the blood glucose levels but have also relatively short half-lives; thus they do not accumulate in plasma [10]. This study examined any possible changes in PK of $\mathrm{RE}$ with concomitant metformin and vice versa.

Data from several clinical studies are highly suggestive that SGLT2 inhibitors, as a class, appear to be safe and efficacious when combined with metformin to treat T2DM [22]. Consistent with these earlier observations

Table 5 Statistical Analysis of accumulation ratio basis PK parameters of Metformin

\begin{tabular}{lll}
\hline PK Parameter & $\begin{array}{l}\text { RE 500 mg + Metformin } \\
\text { (Day 13/Day-1) }\end{array}$ & $\begin{array}{l}\text { RE 750 mg + Metformin } \\
\text { (Day 13/Day-1) }\end{array}$ \\
\hline $\begin{array}{l}\text { AUC } \\
\text { (hr.ng-tau) }\end{array}$ & $1.03(0.97,1.09)$ & $1.01(0.88-1.16)$ \\
$\begin{array}{l}C_{\max } \\
\text { (ng/ml) }\end{array}$ & $0.98(0.9,1.08)$ & $0.96(0.84-1.10)$ \\
\hline
\end{tabular}

$P K=R E$ Remogliflozin Etabonate

Values are point estimate ( $90 \%$ confidence interval) of the geometric leastsquare mean ratio, Day 13 versus Day- 1
[14], RE does not interfere with PK parameters of metformin; the mean $\mathrm{AUC}_{(0-\text { tau }}$ and $\mathrm{C}_{\max }$ values of metformin were found to be comparable between the three groups. Remogliflozin Etabonate was rapidly absorbed following concomitant oral administration with metformin and the active metabolite remogliflozin was also rapidly formed with peak concentration ranging from 0.5 to about $4 \mathrm{~h}$. The accumulation ratios, Day 13 vs. Day 1, for AUC values of RE and its metabolites showed variable observations with the two dose levels tested. However, on background of PK of RE it is important to note that all ratios were all close to 1 , indicating no accumulation in plasma concentrations of RE and its metabolites following multiple-dose administration with concomitant metformin and not indicative of clinically significant changes in plasma exposure. The PK parameters of $\mathrm{RE}$ and its metabolites following $750 \mathrm{mg}$ BID dose with metformin were nearly dose proportional to those following the $500 \mathrm{mg}$ BID dose of RE with metformin. This steady-state plasma profiles of RE and its metabolites observed in this study were comparable to the dose-normalized PK parameter values found previously in T2DM subjects without or with concomitant metformin. These data indirectly suggest that no effect of metformin on the PK profiles of RE and its metabolites, as direct within-study comparison was not possible as RE was only administered with metformin and not alone.

The observation of decrease in the $\mathrm{AUC}_{(0-\text { tau })}$ accumulation ratio for remogliflozin in the $750 \mathrm{mg}$ group would suggest a potential impact on the efficacy of RE. However, the pharmacodynamic assessments showed significant results of RE when concomitantly administered with metformin. Similarly, the Phase III study of RE [23] observed glycemic efficacy comparable to dapagliflozin when administered in T2DM patients on daily metformin therapy (>1500 mg) over 24 weeks. As the efficacy and safety profile of RE is not seen to be affected and clinical doses of RE is lower (100 mg BID), the observed 
Table 6 Summary of Pharmacokinetic Parameters of Remogliflozin Etabonate and its Metabolites

\begin{tabular}{|c|c|c|c|c|c|c|}
\hline \multirow[t]{2}{*}{ Analyte } & \multicolumn{3}{|l|}{$\begin{array}{l}\text { Day } 1 \\
\text { RE } 500 \mathrm{mg} \operatorname{BID}(N=16)\end{array}$} & \multicolumn{3}{|l|}{$\begin{array}{l}\text { Day } 13 \\
\text { RE } 500 \mathrm{mg} \mathrm{BID}(N=15)\end{array}$} \\
\hline & $\begin{array}{l}\text { AUC }_{(0-\text { tau })} \text { or } A U C_{(0-\text { last })}{ }^{a} \\
(\mathrm{hr} . n \mathrm{~g} / \mathrm{ml})\end{array}$ & $C_{\max }(\mathrm{ng} / \mathrm{ml})$ & $\begin{array}{l}\mathrm{t}_{\max } \\
(\mathrm{hr})\end{array}$ & $\begin{array}{l}\mathrm{AUC}_{(0-\text { tau })} \text { or AUC } \\
(\mathrm{hr} . \mathrm{ng} / \mathrm{last}) \\
\left.{ }^{\mathrm{a}} \mathrm{l}\right)\end{array}$ & $\mathrm{C}_{\max }(\mathrm{ng} / \mathrm{ml})$ & $\begin{array}{l}\mathrm{t}_{\max } \\
(\mathrm{hr})\end{array}$ \\
\hline RE & $\begin{array}{l}70.9 \\
(45)\end{array}$ & $\begin{array}{l}64.8 \\
(55)\end{array}$ & $\begin{array}{l}0.63 \\
(0.25-3.0)\end{array}$ & $\begin{array}{l}73.5 \\
(47)\end{array}$ & $\begin{array}{l}53.3 \\
(94)\end{array}$ & $\begin{array}{l}0.50 \\
(0.25-4.0)\end{array}$ \\
\hline Remogliflozin & $\begin{array}{l}4894 \\
(40)\end{array}$ & $\begin{array}{l}1999 \\
(60)\end{array}$ & $\begin{array}{l}0.77 \\
(0.50-6.0)\end{array}$ & $\begin{array}{l}4928 \\
(33)\end{array}$ & $\begin{array}{l}1494 \\
(39)\end{array}$ & $\begin{array}{l}3.0 \\
(0.5-4.0)\end{array}$ \\
\hline $\begin{array}{l}\text { GSK279782 } \\
\text { (active metabolite) }\end{array}$ & $\begin{array}{l}878 \\
(44)\end{array}$ & $\begin{array}{l}257 \\
(51)\end{array}$ & $\begin{array}{l}1.3 \\
(0.75-6.0)\end{array}$ & $\begin{array}{l}1053 \\
(44)\end{array}$ & $\begin{array}{l}251 \\
(49)\end{array}$ & $\begin{array}{l}4.0 \\
(0.5-4.0)\end{array}$ \\
\hline Analyte & $\begin{array}{l}\text { Day } 1 \\
\text { RE } 750 \mathrm{mg} \text { BID }(N=17)\end{array}$ & & & $\begin{array}{l}\text { Day } 13 \\
\text { RE } 750 \mathrm{mg} \text { BID }(N=16)\end{array}$ & & \\
\hline RE & $\begin{array}{l}121 \\
(39)\end{array}$ & $\begin{array}{l}137 \\
(74)\end{array}$ & $\begin{array}{l}0.50 \\
(0.25-2.5)\end{array}$ & $\begin{array}{l}121 \\
(41)\end{array}$ & $\begin{array}{l}101 \\
(74)\end{array}$ & $\begin{array}{l}0.48 \\
(0.22-2.6)\end{array}$ \\
\hline Remogliflozin & $\begin{array}{l}8515 \\
(31)\end{array}$ & $\begin{array}{l}4008 \\
(46)\end{array}$ & $\begin{array}{l}0.75 \\
(0.50-2.5)\end{array}$ & $\begin{array}{l}6996 \\
(39)\end{array}$ & $\begin{array}{l}2508 \\
(65)\end{array}$ & $\begin{array}{l}1.3 \\
(0.50-4.0)\end{array}$ \\
\hline $\begin{array}{l}\text { GSK279782 } \\
\text { (active metabolite) }\end{array}$ & $\begin{array}{l}1600 \\
(50)\end{array}$ & $\begin{array}{l}528 \\
(43)\end{array}$ & $\begin{array}{l}1.0 \\
(0.75-3.0)\end{array}$ & $\begin{array}{l}1298 \\
(42)\end{array}$ & $\begin{array}{l}326 \\
(49)\end{array}$ & $\begin{array}{l}3.0 \\
(0.6-4.1)\end{array}$ \\
\hline
\end{tabular}

$B I D$ twice daily, RE Remogliflozinetabonate

Values are geometric mean $\left(\% \mathrm{CV}_{\mathrm{b}}\right)$ for each parameter, except for $t_{\max }$ which are median (range)

${ }^{a} A \cup C_{(0-t a u)}$ for remogliflozin and GSK279782; $A \cup C_{(0-\text { last })}$ for remogliflozin Etabonate

variations in accumulation ratio can be considered of low clinical relevance.

Results from the pharmacodynamic analysis revealed that mean fasting glucose values decreased in both $\mathrm{RE}$ treatment groups. Reductions in the weighted mean glucose and insulin following an OGTT were also observed, suggesting that the addition of RE may significantly improve glycemia in subjects already taking a higher dose of metformin [23].

Furthermore, a clear reduction in body weight in all the treatment groups was observed. However, the RE cohorts demonstrated a $1 \mathrm{~kg}$ loss more compared to metformin alone. Weight loss could have resulted from changes in both fluid and caloric balance.

Patients with T2DM often have hypertension, which the combination increases the risk for cardiovascular complications. Thus, apart from glycemic control, the modification of cardiovascular risk factors is also important in the management of T2DM. According to the European Society of Hypertension, extreme dipping in case of ambulatory BP can result in stroke [24].
Therefore, regulation of BP likely helps in lowering the risk for cardiovascular complications [25]. In the present analysis, ambulatory BP monitoring measured statistically significant decreases from baseline in systolic (8.4 and $7.1 \mathrm{mmHg}$ ) and diastolic $(6.5$ and $4.8 \mathrm{mmHg}$ ) readings at nighttime on Day 13 for both RE regimens compared to placebo (metformin alone).

The present study revealed that higher doses of RE than used commercially and metformin were generally well tolerated and severe AEs were not reported. The most commonly reported AEs were diarrhea, nausea, thirst, vomiting, and dizziness. This indicates that concomitant administration of RE, either $500 \mathrm{mg}$ BID or $750 \mathrm{mg}$ BID; with metformin $2000 \mathrm{mg}$ (total daily dose) had no effect on the steady-state plasma profiles or pharmacokinetics of metformin.

Addition of RE to ongoing metformin therapy offers a potential for therapeutic benefit without a significant risk of lactic acidosis, hypoglycemia or other AEs. However, as the study was conducted in feasible sample size, the interpretations would need to be considered

Table 7 Statistical Analysis of accumulation ratio basis PK Parameters of RemogliflozinEtabonate and Its Metabolites

\begin{tabular}{|c|c|c|c|c|c|c|}
\hline \multirow[t]{2}{*}{ PK Parameter } & \multicolumn{3}{|c|}{ RE $500 \mathrm{mg}+$ Metformin } & \multicolumn{3}{|c|}{ RE $750 \mathrm{mg}+$ Metformin } \\
\hline & $\mathrm{RE}$ & Remogliflozin & GSK279782 & $\mathrm{RE}$ & Remogliflozin & GSK279782 \\
\hline $\begin{array}{l}\mathrm{AUC}_{(0-\text { tau })} \text { or } \mathrm{AUC}_{(0-\text { last })}{ }^{\mathrm{a}} \\
\text { (hr.ng/ml) }\end{array}$ & $\begin{array}{c}0.99 \\
(0.857-1.15)\end{array}$ & $\begin{array}{c}1.00 \\
(0.907-1.10)\end{array}$ & $\begin{array}{c}1.17 \\
(1.03-1.34)\end{array}$ & $\begin{array}{c}1.02 \\
(0.861-1.21)\end{array}$ & $\begin{array}{c}0.82 \\
(0.755-0.899)\end{array}$ & $\begin{array}{c}0.84 \\
(0.760-0.937)\end{array}$ \\
\hline
\end{tabular}

RE Remogliflozin Etabonate

Values are point estimate (90\% confidence interval) of the geometric least-square mean ratio, Day 13 versus Day 1.

${ }^{\mathrm{a}} \mathrm{AUC} \mathrm{C}_{(0-\text { tau })}$ for remogliflozin and GSK279782; $A \cup C_{(0-\text { last })}$ for RE 
Table 8 Evaluation of Pharmacodynamic Parameters

\begin{tabular}{|c|c|c|c|}
\hline Parameter & $\begin{array}{l}\text { Placebo + Metformin } \\
(\mathrm{N}=17)\end{array}$ & RE $500 \mathrm{mg}+$ Metformin $^{\mathrm{b}}$ & $\begin{array}{l}\text { RE } 750 \mathrm{mg}+\text { Metformin } \\
(N=17)\end{array}$ \\
\hline \multicolumn{4}{|c|}{ Change from Baseline Weighted Mean Plasma Glucose and Insulin } \\
\hline \multicolumn{4}{|c|}{ Glucose (mmol/L), Day 1} \\
\hline Mean (SD) & $12.65(3.306)$ & $13.03(1.929)$ & $11.49(3.536)$ \\
\hline \multicolumn{4}{|c|}{ Glucose (mmol/L), Day 13} \\
\hline Mean (SD) & $11.49(3.536)$ & $9.45(1.502)$ & $8.84(1.656)$ \\
\hline \multicolumn{4}{|c|}{ Glucose, Change from Baseline } \\
\hline Mean (SD) & $-0.10(1.572)$ & $-3.50(2.012)$ & $-2.77(2.262)$ \\
\hline \multicolumn{4}{|l|}{ Insulin (pmol/L), Day -1 } \\
\hline Mean (SD) & $176.85(104.735)$ & $190.96(100.420)$ & $191.52(83.045)$ \\
\hline \multicolumn{4}{|c|}{ Insulin (pmol/L), Day 13} \\
\hline Mean (SD) & 162.97(97.374) & $142.15(67.626)$ & $171.57(74.178)$ \\
\hline \multicolumn{4}{|c|}{ Insulin, Change from Baseline } \\
\hline Mean (SD) & $-13.88(42.349)$ & $-44.80(52.746)$ & $-18.95(47.360)$ \\
\hline \multicolumn{4}{|c|}{ Change from Baseline in Body Weight (kg) } \\
\hline Day 2, Mean (SD) & $-0.70(0.679)$ & $-1.03(0.994)$ & $-1.04(1.210)$ \\
\hline Day14, Mean (SD) & $-1.02(0.845)$ & $-2.03(1.235)$ & $-1.84(1.398)$ \\
\hline \multicolumn{4}{|c|}{ Change in Fluid Balance (ml) } \\
\hline Day 2, Mean (SD) & $203.5(999.83)$ & $-335.3(678.37)$ & $-110.2(1064.69)$ \\
\hline Day13, Mean (SD) ${ }^{a}$ & $-42.0(1262.56)$ & $-610.1(1631.47)$ & $-416.9(493.86)$ \\
\hline
\end{tabular}

RE Remogliflozin Etabonate, SD Standard deviation

${ }^{a}$ Analyzed subjects on Day 13 for RE $500 \mathrm{mg}+$ Metformin group were 15 , ${ }^{\mathrm{b}}$ Analyzed subjects on day 13 for RE $750 \mathrm{mg}+$ Metformin group were 16

exploratory in nature and would require independent evaluation in studies planned with statistically relevant sample sizes.

\section{Conclusion}

The present study concludes that concomitant administration of RE, either $500 \mathrm{mg}$ or $750 \mathrm{mg}$ BID, with metformin $2000 \mathrm{mg}$ BID is safe and effective in patients with T2DM during the observation period. Remogliflozin Etabonate does not affect the PK profile of metformin and improves the plasma blood glucose levels by increasing the excretion of urine glucose.

\section{Acknowledgements}

We acknowledge the contribution of Knowledge Isotopes Pvt., Ltd. (http:// www.knowledgeisotopes.com) for medical writing services for this manuscript development.

\section{Authors' contributions}

$\mathrm{BC}, \mathrm{WW}, \mathrm{KS}$ and $\mathrm{BH}$ prepared and reviewed the manuscript; $\mathrm{RD}$ and $\mathrm{EH}$ contributed to the Protocol design, Study Report, review of manuscript; RS contributed as Coauthor of protocol, and also contributed to the PK analysis, clinical study report and manuscript; SA contributed to the Study design, operational management, study reporting, preparation and review of manuscript; WT contributed to the Biostatistics. All Authors read and approved the manuscript.

\section{Funding}

The design of the study and collection, analysis, and interpretation of data was funded by GSK while the manuscript preparation has been funded by Glenmark Pharma.

\section{Availability of data and materials}

All the relevant data has been represented in the manuscript. Any additional data can be provided by corresponding author on reasonable request.

\section{Declarations}

\section{Ethics approval and consent to participate}

The study protocol was approved by the institutional review board (IRB) and the study was conducted in accordance with the major ethical principles specified in the Declaration of Helsinki and good clinical practice (GCP) guidelines. Written informed consent was obtained from each subject before any study related procedure was performed.

\section{Consent for publication}

Not applicable.

\section{Competing interests}

The authors declare that they have no competing interests. The sponsors were involved in design of the study and collection, analysis, and interpretation of data, and the writing of the manuscript.

\section{Author details}

${ }^{1}$ Indivior, Inc., Durham, NC, USA. ${ }^{2}$ Nuventra, Inc., Durham, NC, USA. ${ }^{3}$ Parexel International, Durham, NC, USA. ${ }^{4}$ GlaxoSmithKline, Collegeville, PA, USA. ${ }^{5}$ Metavant Sciences, Durham, NC, USA. ${ }^{6}$ Avolynt, Inc., RTP, 3920 South Alston Avenue, Durham, NC 27713, USA. ${ }^{7}$ Glenmark Pharmaceuticals Ltd, Mumbai, India. 
Received: 12 August 2020 Accepted: 20 May 2021

Published online: 13 June 2021

\section{References}

1. American Diabetes Association. Diagnosis and classification of diabetes mellitus. Available on: http://www.diabetes.org/living-with-diabetes/ complications/. Accessed 25 Dec 2019.

2. International Diabetes Federation. Diabetes Atlas. Available on: https://www. diabetesatlas.org/. Accessed 25 Dec 2019.

3. Inzucchi SE, Bergenstal RM, Buse JB, et al. Management of hyperglycemia in type 2 diabetes, 2015: a patient-centered approach: update to a position statement of the American Diabetes Association and the European Association for the Study of diabetes. Diabetes Care. 2015;38(1):140-9.

4. Fan $\mathrm{T}$, Koro CE, Fedder DO, et al. Ethnic disparities and trends in glycemic control among adults with type 2 diabetes in the US from 1988 to 2002. Diabetes Care. 2006;29(8):1924-5.

5. Rena G, Hardie DG, Pearson ER. The mechanisms of action of metformin. Diabetologia. 2017;60(9):1577-85

6. Renda F, Mura P, Finco G, et al. Metformin-associated lactic acidosis requiring hospitalization. A national 10 year survey and a systematic literature review. Eur Rev Med Pharmacol Sci. 2013;17 Suppl:145-9.

7. Crowley M, Diamantidis C, McDuffie J, et al:: Metformin Use in Patients with Historical Contraindications or Precautions; Appendix A, FDA Safety Announcements for Metformin. VA ESP Project \#09-010. 2016.

8. Washburn WN. Development of the renal glucose reabsorption inhibitors: a new mechanism for the pharmacotherapy of diabetes mellitus type 2. J Med Chem. 2009;52(7):1785-94.

9. Vallon V, Platt KA, Cunard R, et al. SGLT2 mediates glucose reabsorption in the early proximal tubule. J Am Soc Nephrol. 2011;22(1):104-12.

10. Mikhail N. Remogliflozin etabonate: a novel SGLT2 inhibitor for treatment of diabetes mellitus. Expert Opin Investig Drugs. 2015;24(10):1381-7.

11. Kapur A, O'Connor-Semmes R, Hussey EK, et al. First human dose-escalation study with remogliflozin etabonate, a selective inhibitor of the sodiumglucose transporter 2 (SGLT2), in healthy subjects and in subjects with type 2 diabetes mellitus. BMC Pharmacol Toxicol. 2013:14(1):26.

12. Sykes A, Kemp G, Dobbins R, et al. Randomized efficacy and safety trial of once-daily remogliflozin etabonate for the treatment of type 2 diabetes. Diabetes Obes Metab. 2015;17(1):98-101.

13. Sigafoos JF, Bowers GD, Castellino S, et al. Assessment of the drug interaction risk for remogliflozin etabonate, a sodium-dependent glucose cotransporter-2 inhibitor: evidence from in vitro, human mass balance, and ketoconazole interaction studies. Drug Metab Dispos. 2012;40(11):2090-101.

14. Hussey EK, Kapur A, O'Connor-Semmes R, et al. Safety, pharmacokinetics and pharmacodynamics of remogliflozin etabonate, a novel SGLT2 inhibitor, and metformin when co-administered in subjects with type 2 diabetes mellitus. BMC Pharmacol Toxicol. 2013;14(1):25.

15. Salpeter SR, Greyber E, Pasternak GA, et al. Risk of fatal and nonfatal lactic acidosis with metformin use in type 2 diabetes mellitus: systematic review and meta-analysis. Arch Intern Med. 2003;163(21):2594-602.

16. Andrade EL, Bento AF, Cavalli J, Oliveira SK, Schwanke RC, Siqueira JM Freitas CS, Marcon R, Calixto JB. Non-clinical studies in the process of new drug development - Part II: Good laboratory practice, metabolism, pharmacokinetics, safety and dose translation to clinical studies. Braz J Med Biol Res. 2016;49(12):e5646.

17. Silva Lima B, Videira MA. Toxicology and Biodistribution: The Clinical Value of Animal Biodistribution Studies. Mol Ther Methods Clin Dev. 2018:8:18397.

18. Davis TM, Jackson D, Davis WA, et al. The relationship between metformin therapy and the fasting plasma lactate in type 2 diabetes: the Fremantle diabetes study. Br J Clin Pharmacol. 2001;52(2):137-44.

19. Mudaliar S, Armstrong DA, Mavian AA, et al. Remogliflozin etabonate, a selective inhibitor of the sodium-glucose transporter 2, improves serum glucose profiles in type 1 diabetes. Diabetes Care. 2012;35(11):2198-200.

20. O'Connor-Semmes R, Walker S, Kapur A, et al. Pharmacokinetics and pharmacodynamics of the SGLT2 inhibitor remogliflozin etabonate in subjects with mild and moderate renal impairment. Drug Metab Dispos. 2015;43(7):1077-83.

21. Sykes AP, O'Connor-Semmes R, Dobbins R, et al. Randomized trial showing efficacy and safety of twice-daily remogliflozin etabonate for the treatment of type 2 diabetes. Diabetes Obes Metab. 2015;17(1):94-7.
22. Kalra S. Sodium glucose co-Transporter-2 (SGLT2) inhibitors: a review of their basic and clinical pharmacology. Diab Ther. 2014;5(2):355-66.

23. Dharmalingam M, Aravind SR, Thacker H, Paramesh S, Mohan B, Chawla M, Asirvatham A, Goyal R, Shembalkar J, Balamurugan R, Kadam P, Alva H, Kodgule R, Tandon M, Vaidyanathan S, Pendse A, Gaikwad R, Katare S, Suryawanshi S, Barkate H. Efficacy and Safety of Remogliflozin Etabonate, a New Sodium Glucose Co-Transporter-2 Inhibitor, in Patients with Type 2 Diabetes Mellitus: A 24-Week, Randomized, Double-Blind, Active-Controlled Trial. Drugs. 2020;80(6):587-600.

24. Mancia G, Fagard R, Narkiewicz K, et al. 2013 ESH/ESC guidelines for the management of arterial hypertension: the task force for the Management of Arterial Hypertension of the European Society of Hypertension (ESH) and of the European Society of Cardiology (ESC). Blood Press. 2013;22(4):193-278.

25. Tikkanen I, Narko K, Zeller C, et al. Empagliflozin reduces blood pressure in patients with type 2 diabetes and hypertension. Diabetes Care. 2015;38(3): $420-8$.

\section{Publisher's Note}

Springer Nature remains neutral with regard to jurisdictional claims in published maps and institutional affiliations.
Ready to submit your research? Choose BMC and benefit from:

- fast, convenient online submission

- thorough peer review by experienced researchers in your field

- rapid publication on acceptance

- support for research data, including large and complex data types

- gold Open Access which fosters wider collaboration and increased citations

- maximum visibility for your research: over $100 \mathrm{M}$ website views per year

At $\mathrm{BMC}$, research is always in progress.

Learn more biomedcentral.com/submissions 